\title{
PERBEDAAN PENYERAPAN AIR DAN STABILITAS WARNA BASIS GIGI TIRUAN POLIAMIDA 6 DAN POLIAMIDA MIKROKRISTALIN SETELAH PERENDAMAN
}

Ayu Wanzura, Siti Wahyuni

Departemen Prostodonsia, FKG Universitas Sumatera Utara

E-mail: ayuwanzura40@gmail.com

\section{KATA KUNCI}

Poliamida, penyerapan air, stabilitas warna.

\section{KEYWORDS}

Polyamides, water sorption, color stability.

\begin{abstract}
ABSTRAK
Pendahuluan : Poliamida merupakan bahan yang disarankan sebagai alternatif dari resin akrilik. Poliamida memiliki kelemahan yaitu penyerapan air yang tinggi sehingga berdampak terhadap stabilitas warna poliamida. Pada penelitian ini poliamida yang digunakan adalah poliamida 6 (Bioplast) dan poliamida mikrokristalin (Lucitone FRS). Poliamida Mikrokristalin merupakan poliamida generasi baru yang diciptakan untuk menanggulangi kelemahan - kelemahan pada poliamida sebelumnya. Metode : Jenis penelitian ini adalah experimental laboratoris dan dilaksanakan di Fakultas Kedokteran Gigi USU, FMIPA USU dan Fakultas Farmasi USU. Sampel terdiri dari 24 silinder dengan berukuran diameter $15 \mathrm{~mm} \pm 1 \mathrm{~mm}$ dan ketebalan 0.5 $\mathrm{mm} \pm 0,1 \mathrm{~mm}$ (ISO 4049) dan terbagi menjadi empat kelompok (kelompok A poliamida 6 untuk pengujian penyerapan air, kelompok B poliamida mikrokristalin untuk pengujian penyerapan air, kelompok $\mathrm{C}$ poliamida 6 untuk pengujian stabilitas warna dan kelompok D poliamida mikrokristalin untuk pengujian stabilitas warna). Data dianalisis dengan uji $\mathrm{T}$ Independen. Hasil : Berdasarkan uji $\mathrm{T}$ Independen hasil menunjukkan perbedaan yang signifikan diantara kelompok A dan B ( $\mathrm{p}=0,0001, \mathrm{p}<0,05)$ dan diantara kelompok $\mathrm{C}$ dan $\mathrm{D}$ $(\mathrm{p}=0,012, \mathrm{p}<0,05)$ Simpulan: Poliamida Mikrokristalin memiliki penyerapan air yang lebih rendah dan stabilitas warna yang lebih baik dibandingkan Poliamida 6.
\end{abstract}

\begin{abstract}
Introduction: Polyamide is a recommended material as an alternative of acrylic resin. Polyamide has the disadvantage of high water sorption which impact on the color stability of polyamide. In this study the author used polyamide 6 and microcrystalline polyamides. Microcrystalline polyamide is a new generation of polyamide created to overcome weaknesses in the previous polyamides. Method: This research was experimental laboratory research which conducted at Faculty of Dentistry, Faculty of Mathematics and Natural Science and Faculty of Pharmacy Universitas Sumatera Utara. Sampel consisted of 24 cylinder with a diameter $15 \mathrm{~mm} \pm 1 \mathrm{~mm}$ and the thickness $0.5 \mathrm{~mm} \pm$ $0.1 \mathrm{~mm}$ (ISO 4049) the sample were divided into four groups (group A polyamide 6 for water sorption's test, group B microcrystalline polyamide for water sorption's test, group C polyamide 6 for color stability test and group $D$ microcrystalline polyamide for color stability test). Data were analyzed by Independent T test. Result: Based on the test the results, there show significant differences between groups $A$ and $B(p=0,0001, p<0,05)$ and between groups $C$ and $D(p$
\end{abstract}


$=0,012, p<0,05)$. Conclusion: Microcrystalline polyamide has lower water absorption and good color stability than Polyamide 6.

\section{PENDAHULUAN}

Basis gigi tiruan merupakan bagian dari gigi tiruan yang bersandar pada jaringan lunak rongga mulut dan sebagai tempat dilekatkannya gigi artifisial ${ }^{1}$. Banyak bahan yang disarankan sebagai alternatif dari resin akrilik, salah satunya adalah resin termoplastik poliamida (nilon) ${ }^{2}$. Poliamida atau juga yang dikenal dengan nilon, merupakan jenis polimer yang pada awalnya dikembangkan oleh Carothers pada tahun 1928 - 1938. Poliamida memiliki kelebihan, yaitu nilai estetis yang sangat baik dikarenakan tidak adanya cangkolan logam dan memiliki cangkolan yang sewarna dengan jaringan lunak, bebas dari monomer sisa, fleksibilitas yang tinggi, solubilitas rendah, tahan terhadap suhu tinggi, tahan terhadap bahan kimia dan memiliki sifat tahan terhadap abrasi ${ }^{3,4,5}$. Kelemahan dari poliamida adalah tingkat penyerapan air yang tinggi, terjadinya perubahan warna dan sulit untuk dilakukan reline dan perbaikan ${ }^{6}$. Poliamida memiliki banyak jenisnya, hal ini sesuai dengan jumlah atom karbon yang terdapat pada sepanjang rantai kimia yang membentuk poliamida tersebut. Poliamida 6 dipasaran dikenal dengan Bioplast dan poliamida mikrokristalin yang beredar dipasaran salah satunya adalah Lucitone FRS. Poliamida mikrokristalin merupakan poliamida generasi baru hasil modifikasi yang diciptakan untuk mengatasi kekurangan poliamida sebelumnya. Poliamida 6 memiliki rantai polimer yang pendek dengan berat molekul yang rendah, hal ini dikarenakan semakin panjang rantai suatu polimer maka semakin tinggi berat molekul polimer dan semakin tinggi titik leleh yang dimiliki polimer tersebut. Tingkat kristalinitas poliamida 6 lebih rendah dibandingkan tingkat kristalinitas poliamida mikrokristalin, hal ini juga memengaruhi sifat fisis yaitu penyerapan air dan stabilitas warna dari poliamida 6. Poliamida yang memiliki tingkat kristalinitas rendah lebih cenderung untuk menyerap air sehingga tingkat penyerapan air tinggi ${ }^{7}$. Penyerapan air yang tinggi dapat menyebabkan terjadinya perubahan warna pada bahan basis gigi tiruan sehingga mengurangi masa pemakaian gigi tiruan. Poliamida mikrokristalin memiliki rantai dengan struktur kristalin yang memiliki susunan atom yang teratur, kuat dan $\mathrm{kaku}^{7,8}$. Pada basis gigi tiruan polimer, batas nilai dari penyerapan air menurut ADA adalah $0.8 \mathrm{mg} / \mathrm{cm}^{2}$ dan menurut ISO harus lebih kecil atau sama dengan $32 \mu \mathrm{g} / \mathrm{mm}^{3}{ }^{9}$. Air yang masuk melalui proses difusi pada basis gigi tiruan, akan berperan sebagai plasticizer dengan cara molekul air yang masuk akan menempati bagian amorf pada rantai amida dan memisahkan ikatan rantai, kemudian menempati ruang antar molekul 
sehingga terjadi ekspansi dan menyebabkan ruang intermolekul merenggang dan tingkat penyerapan air menjadi semakin tinggi ${ }^{10}$. Poliamida yang memiliki tingkat kristalinitas tinggi memiliki molekul dengan ukuran yang berat pula, sehingga molekul air lebih sulit dalam memisahkan ikatan antar rantai dikarenakan ukuran molekul yang berat, dan struktur kristal pada molekul merupakan struktur yang tersusun rapi, teratur dan rapat $^{7,8}$. Semakin tinggi tingkat penyerapan air suatu bahan basis gigi tiruan maka semakin tinggi pula nilai yang terserap ke rantai polimer bahan basis gigi tiruan tersebut. Penyerapan air yang terlalu tinggi pada bahan basis gigi tiruan memengaruhi sifat material dan mengakibatkan masa pakai gigi tiruan berkurang, hal ini dikarenakan penyerapan air dari basis gigi tiruan menyebabkan perubahan warna, halitosis dan perubahan dimensi ${ }^{11}$. Perubahan warna pada basis gigi tiruan dapat disebabkan oleh faktor ekstrinsik dan faktor intrinsik. Faktor ekstrinsik yang dapat menyebabkan diskolorasi pada basis gigi tiruan diantaranya adalah kebiasaan minum kopi dan teh, minuman bersoda, cairan pembersih gigi tiruan dan kebiasaan merokok $^{8,12}$. Teh merupakan salah satu jenis tanaman yang terkenal sebagai minuman ${ }^{13}$. Teh hitam merupakan jenis teh yang paling banyak dikonsumsi di Indonesia. Tanin (polifenol) yang dimiliki oleh teh berperan sebagai pemberi warna teh dan sebagai penyebab terjadinya perubahan warna pada basis gigi tiruan. Molekul warna berpenetrasi ke dalam rantai amida dan menempati ruang antar molekul pada rantai amida sehingga menyebabkan terjadinya perubahan warna. Anzharni dkk., meneliti penetapan kadar tanin pada teh celup yang beredar di pasaran dengan menggunakan spektrofotometer dan diperoleh panjang gelombang maksimum katekin adalah $222 \mathrm{~nm}^{14}$. Sari, dkk., (2017) pada penelitiannya menyatakan perendaman sampel dalam larutan selama 7 hari, setara dengan kebiasaan meminum teh selama 1 tahun dengan durasi 15 menit 2 kali dalam sehari ${ }^{8}$.

Maka dari itu, penelitian ini bertujuan untuk mengetahui apakah ada perbedaan sifat fisis pada poliamida yang berbeda dan untuk mengetahui adakah pengaruh perbedaan tingkat kristalinitas pada poliamida terhadap sifat fisis poliamida, yaitu penyerapan air dan stabilitas warna.

\section{METODE}

Rancangan penelitian yang digunakan adalah ekperimental laboratoris. Penelitian ini dilakukan di Unit Jasa Industri Fakultas Kedokteran Gigi Universitas Sumatera Utara, FMIPA Universitas Sumatera Utara dan Fakultas Farmasi Universitas Sumatera Utara. Sampel pada penelitian ini adalah poliamida 6 dan poliamida mikrokristalin berbentuk silindris dengan ukuran diameter $15 \mathrm{~mm} \pm 1 \mathrm{~mm}$ dan tebal $0.5 \mathrm{~mm} \pm 0.1 \mathrm{~mm}$ (ISO 4049) dibagi menjadi empat kelompok dan tiap kelompok berjumlah 6 sampel. 
Kelompok A adalah poliamida 6 untuk uji penyerapan air, kelompok $\mathrm{B}$ adalah poliamida mikrokristalin untuk uji penyerapan air, kelompok $\mathrm{C}$ adalah poliamida 6 untuk uji stabilitas warna dan kelompok D adalah poliamida mikrokristalin untuk uji stabilitas warna.

Pembuatan sampel dilakukan dengan teknik injection moulding yaitu dengan cara dilelehkan dan diinjeksikan ke dalam kuvet di bawah tekanan. Kuvet disiapkan untuk proses injeksi kemudian silinder pemanas dinyalakan hingga panas suhu $\pm 265^{\circ} \mathrm{C}$ untuk pembuatan sampel poliamida 6 dan suhu \pm $301^{\circ} \mathrm{C}$ untuk pembuatan sampel poliamida mikrokristalin. Setelah itu cartridge dimasukkan ke dalam silinder pemanas selama \pm 11 menit agar butiran termoplastik dalam cartridge mencair. Bahan dalam cartridge diinjeksi ke dalam cetakan dengan penekanan sebesar 6-8 bar. Setelah 5 menit, tekanan dilepas dan kuvet dikeluarkan dari alat injeksi dan dibiarkan dingin pada suhu kamar. Kemudian kuvet dibuka, selanjutnya lempeng termoplastik dikeluarkan dari gips menggunakan hook dan mallet.

Setelah sampel dipoles, 12 sampel dimasukkan ke dalam desikator selama 24 jam untuk proses pengeringan. Proses pengeringan ini merupakan prosedur dari uji penyerapan air. Setelah 12 sampel dikeringkan menggunakan desikator dan ditimbang untuk memperoleh nilai W1, kemudian sampel direndam dalam larutan teh selama 7 hari dengan suhu $37^{\circ} \mathrm{C}$ menggunakan incubator. Setelah 7 hari perendaman, sampel dikeluarkan dan dikeringkan dengan menggunakan kain selama 15 detik, kemudian ditimbang untuk memperoleh W2. Setelah diperoleh W2, sampel dimasukkan ke desikator selama 24 jam. Sampel dikeringkan, kemudian ditimbang kembali untuk memperoleh W3.

$$
\text { Penyerapan air }(W s p)=\frac{\mathrm{M} 2-\mathrm{M} 3}{\pi r^{2} \times \mathrm{t}\left(\mathrm{mm}^{3}\right)}
$$

Keterangan :

- Water sorption $(W s p)=$ nilai penyerapan air $\left(\mu \mathrm{g} / \mathrm{mm}^{3}\right)$

- Dry Mass (M1) = berat sampel sebelum perendaman $(\mu \mathrm{g})$

- Wet Mass $(\mathrm{M} 2)=$ berat sampel setelah perendaman $(\mu \mathrm{g})$

- Final dry mass (M3) = besar sampel setelah perendaman dan dikeringkan dengan desikator $(\mu \mathrm{g})$

- $\quad$ Surface area $=$ volume sampel $\left(\mathrm{mm}^{3}\right)$

Sampel untuk pengujian stabilitas warna dihaluskan menggunakan bur frasser. Pengujian stabilitas warna menggunakan alat $U V-V$ is spectrophotometer UV Mini 1800 Shimadzu, Japan. Alat ini hanya dapat membaca sampel dalam bentuk larutan. Oleh karena itu, sampel untuk uji stabilitas warna yang sudah dihaluskan dicampur dengan larutan xylene. Larutan kemudian dipindahkan ke kuvet kaca spektrofotometer, kemudian kuvet ditempatkan pada ruang sampel sumber cahaya ultraviolet dijatuhkan melewati sampel, cahaya yang dipantulkan ke kuvet kaca akan diserap dan dideteksi oleh detektor kemudian ditransfer ke komputer untuk terjemahan pengukuran panjang gelombang dalam satuan $\mathrm{nm}$ dan 
nilai absorbansi. Hasil yang ditampilkan berbentuk grafik dengan sumbu $\mathrm{x}$ menunjukkan sampel dan sumbu $y$ menunjukkan nilai absorbansi warna.

\section{HASIL}

Tabel 1. Nilai rerata dan standar deviasi penyerapan air poliamida 6 dan poliamida mikrokristalin setelah perendaman teh

\begin{tabular}{ccc}
\hline $\begin{array}{c}\text { No } \\
\text { Sampel }\end{array}$ & $\begin{array}{c}\text { Kelompok A } \\
\text { (Poliamida 6) }\end{array}$ & $\begin{array}{c}\text { Kelompok B } \\
\text { (Poliamida } \\
\text { Mikrokristalin) }\end{array}$ \\
\hline 1. & 13,588 & 9,058 \\
\hline 2. & 15,852 & 10,191 \\
\hline 3. & $12,455^{*}$ & $5,661 *$ \\
\hline 4. & 16,985 & 6,794 \\
\hline 5. & $19,249 * *$ & 10,191 \\
\hline 6. & 18,117 & $11,323 * *$ \\
\hline$\overline{\mathrm{x}} \pm$ SD & $\overline{\mathrm{x}} \pm$ SD 16,041 & $\overline{\mathrm{x}} \pm$ SD 8,869 \pm \\
& $\pm 2,623$ & 2,197 \\
\hline
\end{tabular}

Tabel 1 menunjukkan hasil nilai penyerapan air, rerata, dan standar deviasi tiap kelompok. Nilai rerata penyerapan air yang tertinggi terdapat pada kelompok A (poliamida 6) yaitu $16,041 \pm 2,623 \mu \mathrm{g} / \mathrm{mm}^{3}$ dan yang terendah terdapat pada kelompok B (poliamida mikrokristalin) yaitu 8,869 \pm $2,197 \mu \mathrm{g} / \mathrm{mm}^{3}$.

Tabel 2. Hasil uji T Independen

\begin{tabular}{cccc}
\hline \multirow{2}{*}{ Kelompok } & \multicolumn{3}{c}{ Penyerapan Air } \\
\cline { 2 - 3 } & $\mathrm{n}$ & $\overline{\mathrm{x}} \pm \mathrm{SD}$ & $\mathrm{p}$ \\
\hline $\mathbf{A}$ & 6 & $16,041 \pm 2,623$ & \\
\hline B & 6 & $8,869 \pm 2,197$ & $0,0001^{*}$ \\
\hline
\end{tabular}

Berdasarkan hasil uji $\mathrm{T}$ Independen menunjukkan hasil perbedaan yang signifikan antara Kelompok A dan B $(p=0,0001, p<0,05)($ Tabel 2).

Tabel 3. Nilai rerata dan standar deviasi stabilitas warna poliamida 6 dan poliamida mikrokristalin

\begin{tabular}{ccc}
\hline $\begin{array}{c}\text { No. } \\
\text { Sampel }\end{array}$ & $\begin{array}{c}\text { Kelompok C } \\
\text { (Poliamida 6) }\end{array}$ & $\begin{array}{c}\text { elompok D } \\
\text { (Poliamida } \\
\text { Mikrokristalin) }\end{array}$ \\
\hline 1. & $4,0000 * *$ & $1,4264 *$ \\
\hline 2. & 2,7267 & 1,5806 \\
\hline 3. & 2,6177 & 1,5506 \\
\hline 4. & 2,6969 & $2,2496 * *$ \\
\hline 5. & 2,4257 & 1,6475 \\
\hline 6. & $1,9187 *$ & 2,1406 \\
\hline $\bar{x} \pm$ SD & $\overline{\mathrm{x}} \pm$ SD 2,73095 \pm & $\overline{\mathrm{x}} \pm$ SD 1,765 \pm \\
0,689 & 0,341 \\
\hline setelah perendaman teh
\end{tabular}

Tabel 3 menunjukkan nilai hasil uji stabilitas warna, rerata, dan standar deviasi tiap kelompok. Nilai rerata stabilitas warna yang tertinggi terdapat pada kelompok A (poliamida 6) yaitu 2,73095 $\pm 0,689$ dan yang terendah terdapat pada kelompok B (poliamida mikrokristalin) yaitu 1,765 \pm 0,341 .

Tabel 4. Hasil uji T Independen

\begin{tabular}{cccc}
\hline \multirow{2}{*}{ Kelompok } & \multicolumn{3}{c}{ Stabilitas Warna } \\
\cline { 2 - 3 } & $\mathrm{n}$ & $\overline{\mathrm{x}} \pm \mathrm{SD}$ & $\mathrm{p}$ \\
\hline C & 6 & $2,73095 \pm 0,689$ & $0,0012^{*}$ \\
\hline $\mathbf{D}$ & 6 & $1,765 \pm 0,341$. & \\
\hline
\end{tabular}

Berdasarkan hasil uji $\mathrm{T}$ Independen menunjukkan hasil perbedaan yang signifikan antara Kelompok C dan D $(\mathrm{p}=0,0012, \mathrm{p}<0,05)($ Tabel 4).

\section{PEMBAHASAN}

Hasil penelitian menunjukkan bahwa nilai penyerapan air dan stabilitas warna bervariasi pada tiap kelompok. Hal ini dapat disebabkan oleh mikroporositas yang terbentuk karena udara yang masuk selama proses pemanasan pada saat nilon 
dimanipulasi melalui proses injection moulding. Poliamida mikrokristalin memiliki titik leleh yang lebih tinggi dibandingkan titik leleh poliamida 6 yaitu $\pm 301^{\circ} \mathrm{C}$ dan poliamida 6 memiliki titik leleh $\pm 265^{\circ} \mathrm{C}$. Titik leleh poliamida tergantung dari panjang rantai yang dimiliki suatu poliamida. Semakin tinggi titik leleh suatu poliamida maka smakin panjang rantai poliamida tersebut dan semakin tinggi berat molekul yang dimiliki poliamida tersebut. Poliamida yang memiliki jumlah atom karbon yang sedikit pada rantainya, memiliki rantai yang pendek dan lebih mudah untuk menyerap air jika dibandingkan dengan poliamida yang memiliki rantai yang lebih panjang. Poliamida memiliki kelompok polar pada rantai amidanya dan hal ini memengaruhi sifat dari poliamida. Ariyani (2016) dalam penelitian nya menyatakan poliamida termoplastik merupakan polimer yang memiliki sifat hidrofilik sehingga mudah untuk menyerap air sehingga berdampak terhadap stabilitas warna basis gigi tiruan ${ }^{12}$. Poliamida merupakan polimer yang tidak peka terhadap larutan nonpolar, namun dikarenakan adanya kelompok polar pada rantai amida menyebabkan poliamida peka terhadap larutan polar, tidak terkecuali air. Air berperan sebagai plasticizer yang memiliki kemampuan untuk memisahkan ikatan rantai polimer dengan cara menempati ruang di antara rantai polimer sehingga memperbesar jarak antara rantai yang dapat menyebabkan terjadinya perubahan dimensi pada basis gigi tiruan ${ }^{7,10}$.

Proses penyerapan air pada basis gigi tiruan terbagi atas dua proses, yaitu proses adsorpsi dan absorpsi. Proses adsorpsi adalah jumlah air yang terserap pada permukaan basis gigi tiruan, sedangkan absorbsi adalah proses penyerapan air ke dalam basis gigi tiruan ${ }^{15}$. Nilai rerata penyerapan air yang tinggi pada poliamida 6, dikarenakan molekul air mudah untuk menembus ruang antar molekul pada poliamida 6. Poliamida 6 memiliki rantai yang pendek, berat molekul dan tingkat kristalinitas yang rendah sehingga memudahkan molekul air untuk menmpati ruang antar molekul. Poliamida mikrokristalin memiliki tingkat kristalinitas tinggi, sehingga struktur atom pada rantai amida poliamida mikrokristalin rapat, kuat, teratur dan kaku. Hal ini menyebabkan molekul air sulit untuk menembus rantai poliamida mikrokristalin sehingga poliamida mikrokristalin memiliki tingkat penyerapan air yang rendah dan stabilitas warna yang lebih baik jika dibandingkan dengan poliamida 6. Semakin tinggi tingkat penyerapan air poliamida, maka semakin rendah stabilitas warna poliamida tersebut. Dari hasil penelitian menunjukkan, nilai rerata penyerapan air dari poliamida mikrokristalin hampir setengah dari nilai rerata poliamida 6 , hal ini menunjukkan poliamida mikrokristalin memiliki stabilitas warna yang lebih baik. Air masuk ke dalam basis gigi tiruan melalui proses difusi, 
molekul air menempati ruang antar molekul pada rantai polimer dikarenakan molekul air memiliki ukuran yang kecil yaitu kurang dari $0,28 \mathrm{~nm}^{15}$.

Pada saat proses penyeduhan teh, tanin yang mengandung pigmen akan terlarut dalam air kemudian saat dikonsumsi larutan teh berkontak dengan basis gigi tiruan dan zat warna yang dimiliki teh masuk ke dalam ruang antar rantai yang ada pada poliamida bersamaan dengan masuknya molekul air ke dalam rantai amida. Semakin tinggi penyerapan air bahan basis gigi tiruan, maka semakin tinggi juga kelompok sampel menyerap zat warna sehingga basis gigi tiruan ini memiliki stabilitas warna yang buruk. Pada penelitian ini menunjukkan kelompok sampel poliamida 6 memiliki sifat fisis yang lebih buruk jika dibandingkan dengan poliamida mikrokristalin.

\section{SIMPULAN}

Hasil penelitian ini, menunjukkan bahwa poliamida mikrokristalin memiliki penyerapan air dan stabilitas warna yang lebih baik daripada poliamida 6 serta poliamida mikrokristalin memiliki durabilitas yang baik. Poliamida mikrokristalin merupakan bahan basis gigi tiruan yang tepat bagi pasien yang mengalami beberapa kehilangan gigi pada daerah yang membutuhkan sedikit tekanan dan mengutamakan estetis seperti gigi insisivus dan premolar.

\section{DAFTAR PUSTAKA}

1. Mc Cabe JF, Walls AWG, Applied dental material,. $9^{\text {th }}$ ed, Oxford Blackwell Publishing, England, 2008. Waters sorption and solubility of polyamide denture base materials

2. Nguyen LG, Kopperud HM, Oilo M, Acta Biomaterialia Odontologica Scandinavica, Volume 3, No. 1:47-52, (April 2017), doi: 10.1080/23337931.2017.1326009

3. Kohli S, Bhatia S, Polyamides in dentistry, International Journal of Scientific Study, Volume 1 No.1: 20-25, (April - Juni 2013)

4. Nandal S, Ghalaut P, Shekwawat H, Gulati MS, New era in denture base resins, Dental Journal of Advance Studies, Volume 1 No.3: 136-143, (2013), doi : 10.1055/s-0038-1671969

5. Ardelean L, Bortun C, Podariu A, Rusu L, Manufacture of different types of thermoplastic, In: Sobati AZE, Thermoplastic - composite materials, Intech, Croatia, 2012

6. Fueki K, Yatabe M, Arita M, Kanamori T, Kawara $\mathrm{M}$, Suzuki T, et al, Clinical application of removable partial dentures using thermoplastic resin part II, Journal of Prosthodontics Research, $\begin{array}{lllll}\text { Volume } & 58 \quad: & 71-84 & \text { (2014), }\end{array}$ https://doi.org/10.1016/j.jpor.2014.03.002

7. Anusavice KJ, Shen C, Rawls HR, Phillips' science of dental materials, $12^{\text {th }}$ ed, Elsevier, USA, 2013

8. Sari, Fardaniah S, Masulili C. Color changing in denture base polyamide 12 and polyamide microcrystalline after polishing in laboratory and dental clinic, Journal of Physics: 1-6 (2017), doi $: 10.1088 / 1742-6596 / 884 / 1 / 012100$

9. Hemmati MA, Vafaee F, Allahbakshi H, Water sorption and flexural strength of thermoplastic and conventional heat - polymerized acrylic resins, Journal of Dentistry, Volume 13 No.7 : 478 - 484 (Juli 2015)

10. Carr AB, Browman DT. McCracken's Removable Partial Prosthodontics, $12^{\text {th }}$ ed, Elsevier, Canada, 2011.

11. Dae-Eun J, Ji-Young L, Hyun-Seon J, Jang-jae L, Mee-Kyoung S, Color stability, water sorption and cytotoxicity of thermoplastic acrylic resin for non metal clasp denture, Journal Advanced Prosthodontics, Volume 7 : 278-87 (2015), https://doi.org/10.4047/jap.2015.7.4.278

12. Ariyani, Nasution ID, Agusnar A, Effect of thermocycling and e-glass fiber addition on water sorption and color stability of thermoplastic nylon denture base material, Journal of Dental and Medical Sciences, Volume 15 No. 6 : 41-8 (2016), doi: 10.9790/0853-1508024148

13. Sudaryat Y, Kusmiyati M, Pelangi CR, Rustamsyah A, Rohdiana D, Aktivitas antioksidan seduhan sepuluh jenis mutu teh hitam (Camellia sinensis (L.) O. Kuntze) Indonesia, Jurnal Penelitian Teh dan Kina, Volume 18 No.2 : 95-100 (2015)

14. Fajrina A, Jubahar J, Sabirin S, Penetapan Kadar Tanin pada Teh Celup yang Beredar di Pasaran secara Spektrofotometri Ultraviolet Sinar Tampak, Jurnal Sains dan Teknologi Farmasi, Volume 19 
Wanzura : Perbedaan penyerapan air dan stabilitas warna...

No. 1: 17 - 21 (2017), doi: 0.4103/09731482.148700

15. Ariyani. Pengaruh Penambahan Fiber Glass Reinforced Terhadap Penyerapan Air dan Stabilitas
Warna Bahan Basis Gigi Tiruan Nilon Termoplastik, Thesis Program Pendidikan Dokter Gigi Spesialis Prostodonsia, Universitas Sumatera Utara, Medan, 2015, Tidak Dipublikasikan. 